${ }^{\star}$ Departments of Medical Immunology, and 'Departments of Neurology and Experimental Neurology, Charité, Humboldt University, 10098 Berlin, Germany. Institute of Brain Research, EberhardKarls University Tübingen, Calwerstr. 3, 72076

Tübingen, Germany. ${ }^{5} \mathrm{CNRS}$ UMR 7102, Université Pierre et Marie Curie (VI), Equipe Developpement Neuronal,

Batiment B, Case 12, 9 Quai Saint Bernard, 75005 Paris, France. "Present address: The Brigham and Women's Hospital, Center for Experimental Therapeutics, 75 Francis Street, Thorn 724, Harvard Medical School, Boston 02115,

Massachusetts, USA. Correspondence to J.M.S. e-mail:jschwab@zeus.bwh. harvard.edu

doi:10.1038/nrn1765

Published online

15 September 2005

\title{
CENTRAL NERVOUS SYSTEM INJURY-INDUCED IMMUNE DEFICIENCY SYNDROME
}

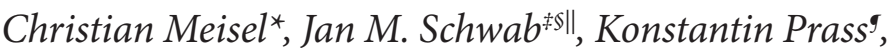 \\ Andreas Meisel' and Ulrich Dirnagl ${ }^{9}$
}

Abstract | Infections are a leading cause of morbidity and mortality in patients with acute CNS injury. It has recently become clear that CNS injury significantly increases susceptibility to infection by brain-specific mechanisms: CNS injury induces a disturbance of the normally well balanced interplay between the immune system and the CNS. As a result, CNS injury leads to secondary immunodeficiency - CNS injury-induced immunodepression (CIDS) - and infection. CIDS might serve as a model for the study of the mechanisms and mediators of brain control over immunity. More importantly, understanding CIDS will allow us to work on developing effective therapeutic strategies, with which the outcome after CNS damage by a host of diseases could be improved by eliminating a major determinant of poor recovery.

Infections are a leading cause of death in patients with acute CNS injury, such as stroke, traumatic brain injury (TBI) and spinal cord injury (SCI). In affected patients, infections impede neurological recovery and increase morbidity as well as mortality. Infections after CNS injury may be attributed to exposure of these patients to invasive medical procedures and hospitalization, dysphagia and aspiration, bladder dysfunction, and so on. However, it has become clear that CNS injury is an independent risk factor, which, through specific mechanisms, significantly increases susceptibility to infection. It has only recently been realized that CNS injury induces a disturbance of the normally well balanced interplay between the immune system and the CNS, and that this is the mechanism by which CNS injury leads to secondary immunodeficiency (CNS injury-induced immunodepression, CIDS) and infection.

The CNS senses inflammation in the body through the autonomic nervous system, and mounts a strong counter-regulatory response in case of systemic infection or injury. This response is anti-inflammatory and immunodepressant in nature, and can be considered adaptive, as it helps to contain infection- and injury-induced inflammation when they occur in the periphery. Brain or spinal cord injury can lead to the production of inflammatory mediators in the CNS, or disruption of signalling in the control circuitry of neural-immune interactions, both of which may also lead to systemic downregulation of INNATE AND ADAPTIVE IMMUNITY. However, in the absence of immune stimulation by peripheral inflammation this leads to profound deficiencies of the body's defence systems, which leaves the host vulnerable to invading microorganisms.

In this article, we review the clinical and experimental evidence for CIDS after CNS injury, and compare it with other medical conditions in which the brain modulates the immune system, such as during systemic inflammation or trauma. We focus on stroke, TBI and SCI, as CIDS induced by these prototypical acute CNS disorders is best understood. As CIDS is an important contributor to the negative outcome for patients with brain injury, there is an urgent need to raise the awareness of CIDS in physicians treating patients with acute CNS injury, to understand its mechanisms and to devise therapeutic countermeasures. 


\section{Infection as a result of CNS injury}

There is overwhelming clinical evidence that infection is a highly relevant complication in three major injury conditions of the CNS: TBI, stroke and SCI.

Stroke. The prognosis of STROKE patients is mainly dependent on the occurrence of medical complications ${ }^{1}$. In a prospective study, up to $85 \%$ of stroke patients experienced complicating events during acute care ${ }^{2}$. The most frequently occurring medical complications of stroke are fever and pneumonia ${ }^{3}$. The association between stroke and fever had already been recognized more than 160 years ago ${ }^{4}$. Fever occurs in up to $61 \%$ of all stroke patients during the acute phase $\mathrm{e}^{5}$ and has a negative effect on stroke outcome $^{6,7}$. The main cause of fever in stroke patients is infection ${ }^{8}$, in particular pneumonia and urinary tract infections ${ }^{1,9}$. Pneumonia is the most common serious medical complication in stroke care ${ }^{9,10}$, occurring in up to $22 \%$ of all stroke patients. Stroke-associated pneumonia increases acute and long-term mortality 2.5 -fold, and is the most frequent cause of death in the post-acute phase $\mathrm{e}^{1-14}$. In many patients, strokeassociated pneumonia is an early complication ( $58 \%$ of pneumonias develop within $48 \mathrm{~h})^{1,2,5,15}$. The high incidence of infection abides over time, with a cumulative incidence of about $50 \%$ during the rehabilitation phase $^{10}$.

The incidence of pneumonia correlates with stroke severity ${ }^{16}$, infarct location ${ }^{15}$, impairment of protective reflexes ${ }^{17}$, dysphagia and mechanical ventilation ${ }^{15}$, as well as neurological deficit. However, although stroke-induced pneumonia, aspiration alone is not sufficient to induce pneumonia: approximately half of all healthy adults aspirate during sleep without severely affected patients are at risk: even silent cerebral infarcts are related to a higher incidence of pneumonia ${ }^{20}$.

The early phases of the host response to a pathogen depend on innate resistance

mechanisms. The activation of innate effector mechanisms induces the clonal expansion of antigen-specific lymphocytes and initiates adaptive immune responses, including the development of immunological memory.

\section{STROKE}

There are two main types of stroke: ischaemic (caused by blockage in an artery that supplies blood to the brain) and haemorrhagic (caused by the bleeding of ruptured blood vessels in the brain).

NOSOCOMIAL

A disease acquired in hospital.

HYPOXAEMIA

Describes critically decreased

arterial oxygen levels. Traumatic brain injury (TBI). NOSOCOMIAL infections are common extracranial complications in patients with head injuries ${ }^{21,22}$. The frequent need for mechanical ventilation places patients with severe traumatic brain injuries at particular risk of developing ventilator-associated pneumonia (VAP). The overall incidence of VAP in patients receiving mechanical ventilation ranges from $8 \%$ to $28 \%{ }^{23}$, but can reach $60 \%$ in patients with neurotrauma, which shows the high susceptibility to infections of this particular pathology $21,24-26$. Risk factors for VAP include trauma severity, aspiration and nasal carriage of Staphyloccocus aureus on admission ${ }^{24,27,28}$. In addition, the use of high dose barbiturates and treatment with hypothermia for the management of intracranial hypertension after brain injury may increase susceptibility to infections $s^{24,29,30}$. Although ventilated intensive care unit patients with VAP seem to have a higher risk of death compared with patients without pneumonia ${ }^{21}$, whether VAP independently contributes to mortality aspiration is the commonly cited explanation for developing pneumonia ${ }^{18,19}$. In addition, not only

in patients with TBI is controversial. Some investigators have reported pneumonia, particularly late onset pneumonia due to certain pathogens (for example, Pseudomonas aeruginosa and Acinetobacter spp), to be an independent risk factor for mortality after TBI, whereas other studies found no excess mortality attributable to pneumonia in these patients ${ }^{21,22,25,31,32}$. However, pneumonia is associated with fever, HYPOXAEMIA, arterial hypotension and intracranial hypertension, which are known to worsen the neurological outcome of patients with brain injuries ${ }^{24}$.

Spinal cord injury (SCI). Infectious complications, predominantly pulmonary and urinary tract infections, occur frequently within the first days after $\mathrm{SCI}^{33,34}$. Although early mortality is due to direct complications of other organ systems, infections are the leading cause of death in the post-acute phase following $\mathrm{SCI}^{35,36}$. The incidence of pneumonia is higher in patients with complete tetraplegia (38\%) than in those with complete paraplegia (15\%).

It is of note that the incidence of pneumonia in patients not undergoing surgery (spine-stabilization or other) has been shown to be similar to that in those undergoing surgery, which suggests that surgery-induced 'post-aggression syndrome' is of minor relevance, with injury of the spinal cord being the determining factor ${ }^{37}$. This view is further supported by the fact that patients develop drastic immunodepression after SCI, whereas patients undergoing lower limb surgery show no or only minor immunosuppression. Furthermore, despite its well known immunodepressant effects, iatrogenic application of high dose methylprednisolone, a common treatment after SCI, is not the determining factor of post-SCI immunodepression, as rats with or without high dose methylprednisolone treatment develop similar immune deficiency after experimental SCI (T. Riegger, S. Conrad, H. J. Schluesener, H.-P. Kaps, C. Baron, J. Gerstein, K. Dietz, M. Adibzahdeh, R. Meyermann and J.M.S., unpublished observations).

Almost $50 \%$ of the deaths that occur subsequent to SCI are due to infections, such as pneumonia or septicaemia. Reines and Harris ${ }^{38}$ reported an attributed mortality rate of $11 \%$ for patients with SCI due to pulmonary complications. Pneumonia was the leading cause of death during a period of 12 years after injury ${ }^{35}$. Pneumonia occurs more frequently in patients with extensive SCI than in patients with milder injury.

Surprisingly, pneumonia was diagnosed late, at an average of 25 days following injury ${ }^{33}$. In addition, recent evidence shows that infections and associated hyperthermia are linked with worse neurological outcomes after CNS injury ${ }^{39,40}$. Therefore, current evidence suggests that clinically relevant infections are common after SCI, and that they have an important impact on outcome after SCI. injury is associated with a high risk of infection, and that the consequences of these infections for outcome are profound (TABLE 1). This holds true not only for
As reviewed above, there is ample evidence that CNS 


\begin{tabular}{|c|c|c|c|c|}
\hline Injury & Incidence (per million) & Rate of infection & Attributed mortality & Typical infections \\
\hline Stroke & $2,000-3,500$ & $16-23 \%$ & $>30 \%$ (acute) & $\begin{array}{l}\text { Pneumonia, urinary } \\
\text { tract infections }\end{array}$ \\
\hline $\begin{array}{l}\text { Traumatic } \\
\text { brain injury }\end{array}$ & 1,600 & $21-60 \%$ & up to $6.7 \%$ & $\begin{array}{l}\text { Pneumonia, } \\
\text { septicaemia, urinary } \\
\text { tract infections }\end{array}$ \\
\hline $\begin{array}{l}\text { Spinal cord } \\
\text { injury }\end{array}$ & $30-60$ & $28-38 \%$ & $4.4-16.7 \%$ & $\begin{array}{l}\text { Cystitis, pneumonia, } \\
\text { pancreatitis, wound } \\
\text { infections }\end{array}$ \\
\hline
\end{tabular}

the acute phase but also for the chronic phase. Even in patients with chronic CNS injury, peripheral infection or inflammation exacerbates CNS symptoms. But why are patients with CNS injury at such a high risk of infection? They often have complicating peripheral injury (polytrauma), undergo invasive medical treatment (such as surgery, catheterization and mechanical ventilation), may be immobilized and exposed to various multiple-drug-resistant bacteria, and may have CNS lesions that specifically impair their ability to swallow - leading to aspiration - and/or cause retention of urine. These factors, alone or in combination, seem sufficient to explain the high incidence of infection. Below, we review evidence that CNS injury can directly induce immunodepression, and that this may explain the high risk of infection in patients with CNS injury. We show that CIDS results in profound deficiencies of the body's defence systems, which leaves the host susceptible to infection at a time when efficient immunity is desperately needed.

\section{Cell-mediated immune responses}

A host of studies have demonstrated immune dysfunction after CNS injury ${ }^{41-45}$. Although the initial local response to brain damage is pro-inflammatory and accompanied by a systemic response comprising features of the SYSTEMIC INFLAMMATORY RESPONSE SYNDROME (SIRS), patients with injuries of the CNS also show signs of systemic immunosuppression ${ }^{28,46}$. Commonly reported defects in immune function in patients after stroke, TBI or SCI include reduced peripheral blood lymphocyte counts and impaired $\mathrm{T}$ - and natural killer (NK)-cell activity. There is evidence that peripheral blood T-lymphocytes obtained from patients with CNS injury show reduced mitogen-induced cytokine production and proliferation in vitro $o^{41,42,47,48}$. The response rate of patients with brain trauma to the anergic delayed-type hypersensitivity (DTH) skin test was found to correlate with trauma severity ${ }^{48,49}$. Similarly, decreased natural killer (NK) cell counts and cytotoxic activity was observed in these patients ${ }^{41,50,51}$. In contrast to impaired T- and NK-cell functions, HUMORAL immune responses seem less affected after CNS injury ${ }^{47,50,52}$. Trauma-induced immunosuppression is also reflected by impaired phagocytotic activity of granulocytes and by monocyte deactivation ${ }^{45,53,54}$.
Circulating monocytes from patients with acute brain injury have decreased expression of major histocompatibility complex (MHC) class II and a profoundly reduced capacity to produce pro-inflammatory cytokines in response to ex vivo stimulation with ENDOTOXIN $^{45,54}$. Impaired monocyte functions result in insufficient antigen-presentation and decreased expression of secreted or membrane-bound costimulatory molecules and may, therefore, contribute to reduced lymphocyte responses ${ }^{55}$.

In general, changes in cellular immune responses correlate with the severity of brain injury. They occur rapidly - within hours after the injurious insult and can last for up to several weeks ${ }^{41-43}$. In addition, the extent and duration of impaired cell-mediated immune responses in patients with CNS injuries often correlate with an increased risk of infection and poor outcome ${ }^{45,56,57}$. The importance of impaired cellular immune responses for the increased susceptibility to infection after CNS injury was recently shown by Prass et al. ${ }^{58}$ in a mouse model of cerebral ischaemia. Stroke induced a rapid and extensive apoptotic loss of lymphocytes in lymphoid organs and peripheral blood, which was observed as early as $12 \mathrm{~h}$ after cerebral ischaemia. Cellular dysfunction was evident by the decreased production of lymphocytic interferon- $\gamma$ (IFN $\gamma$ ) and monocytic tumour necrosis factor- $\alpha$ (TNF $\alpha$ ). Immune dysfunctions were observed for up to 6 weeks after stroke. Importantly, mice spontaneously developed systemic bacterial infections 1-3 days after cerebral ischaemia, well after first signs of immunosuppression were observed. Immune reconstitution by adoptive transfer of IFN $\gamma$-producing lymphocytes (that is, T and NK, but not B cells) from healthy littermates or treatment with recombinant IFN $\gamma$ greatly diminished bacterial burden, demonstrating a causative link between suppression of cell-mediated immune responses and increased susceptibility to bacterial infections.

In summary, substantial clinical and experimental evidence points towards a major role of impaired cellmediated immune responses in the high incidence of infectious complications after CNS injury. Brain injury leads to a characteristic immunological phenotype, which is immunodepressant. To understand how and why CNS injury induces immunodepression, we have to explore the mechanisms by which the immune system and CNS interact. 


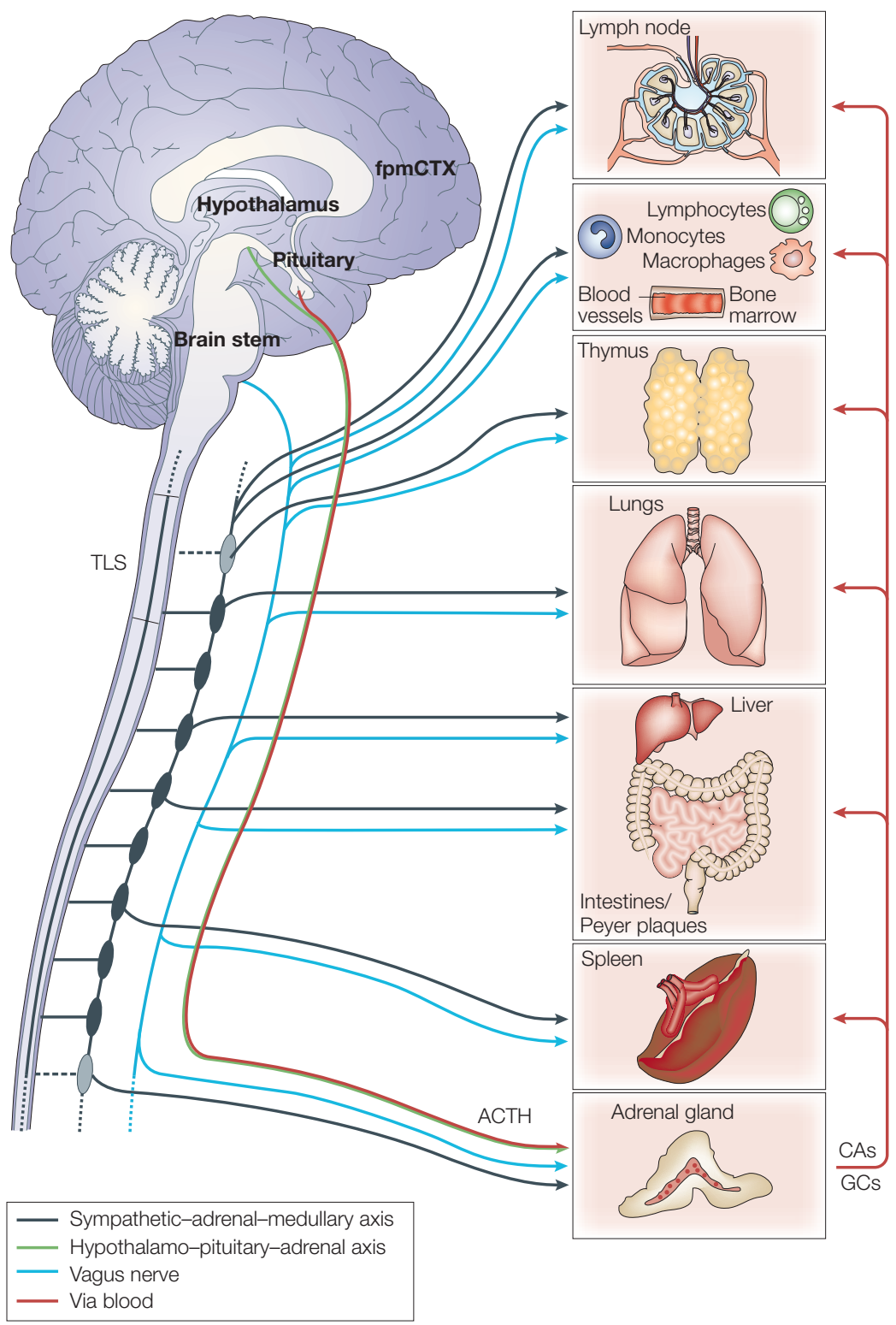

Figure 1 | The nervous and immune systems are engaged in bidirectional communication. Sensors within the central and peripheral autonomic nervous systems relay information about the status of the immune system. This input is processed by the CNS, in particular the frontal premotor cortex (fpmCTX), the hypothalamus, the pituitary and the brain stem. This processing results in homeostatic signals being sent to various sites in the body via three major pathways of neuroimmunomodulation: the hypothalamopituitary-adrenal (HPA) axis, the sympathetic-adrenal-medullary (SAM) axis and the parasympathetic nervous system (vagus nerve). Activation of the HPA and the SAM axes results in production of glucocorticoid hormones (GCs) and catecholamines (CAs). ACTH, adrenocorticotropic hormone; TLS, thoraco-lumbar system. the hypothalamo-pituitary-adrenal (HPA) axis, the sympathetic nervous system (SNS) and the parasympathetic nervous system ${ }^{59-61}$. FIGURE 1 and TABLE 2 give an overview of the relevant anatomical pathways and structures, which are reviewed below in more detail.

Sensing of inflammation by the CNS. Today, we know of at least two pathways by which the brain senses inflammation: a neural (mainly by the vagus nerve) and a humoral pathway (for reviews, see REFS 62,63). Inflammation leads to the production of cytokines (for example, TNF, interleukin-1 $\beta$ (IL-1 $\beta$ ) and IL-6), which can either engage with their cognate receptors outside the CNS - on local afferent fibres of the vagal nerve ${ }^{64}-$ or after entry from the bloodstream into the brain, with receptors in the CNS. Passage into the brain of these large molecules may occur actively, through carrier-mediated mechanisms ${ }^{65}$, or passively, through the capillary endothelium of circumventricular organs that lack blood-brain barrier properties ${ }^{66}$. The circumventricular organs include the pineal gland, the subfornical organ, the median eminence, the neural lobe of the pituitary, the subcommissural organ and, importantly, the organum vasculosum of the lamina terminalis ${ }^{67}$. The circumventricular organs are central relays of neuroendocrine and neuroimmune signalling, through which information about the immune status is fed into sympathetic and parasympathetic processing. Alternatively to direct brain access, cytokines in the blood stream may act at intact sites of the blood-brain barrier through receptors on brain endothelial cells, where they induce the abluminal release of diffusible mediators, such as nitric oxide and prostaglandin E2.

Cytokines arising from injury-induced inflammation in the CNS may access control centres of neural-immune interaction directly, via diffusion in the extracellular space and cerebrospinal fluid, or indirectly, via the bloodstream. In general, cytokine receptors relevant for CNS-immune communication in the brain are preferentially located in the circumventricular organs and the medial preoptic area, from which the signal is relayed to the paraventricular nucleus (PVN) of the hypothalamus through neural projections ${ }^{68}$.

The hypothalamus. Besides that from the preoptic area, the hypothalamus receives input from many other CNS regions, including the nucleus tractus solitarius -(NTS), formatio reticularis, the retina and the insular cortex, all of which modulate its activity and output. Through the release of corticotropin-releasing factor (CRF) from its PVN, the hypothalamus modulates the HPA axis and the SNS. Descending projections to brain stem centres (for example, the NTS) affect vagal output. In addition, CRF neurons in the hypothalamus can respond directly, to cytokines, as well as to autonomic input. For example, vagal input is connected to the hypothalamus directly, via the NTS, and indirectly, via the locus coeruleus. 


\begin{tabular}{|c|c|c|c|}
\hline Variable & SNS & HPA axis & N. Vagus \\
\hline $\begin{array}{l}\text { Triggers } \\
\text { (CIDS only) }\end{array}$ & $\begin{array}{l}\text { Neurogenic (Disinhibition } \\
\text { or excitation of autonomic } \\
\text { nervous system through lesion) } \\
\text { Inflammatory cytokines (locally } \\
\text { produced) }\end{array}$ & $\begin{array}{l}\text { Neurogenic (Disinhibition } \\
\text { or excitation of autonomic } \\
\text { nervous system through lesion) } \\
\text { Inflammatory cytokines (locally } \\
\text { produced) }\end{array}$ & $\begin{array}{l}\text { Neurogenic (Disinhibition or } \\
\text { excitation of autonomic nervous } \\
\text { system through lesion) } \\
\text { Inflammatory cytokines (locally } \\
\text { produced) }\end{array}$ \\
\hline $\begin{array}{l}\text { Triggers } \\
\text { (CARS and } \\
\text { CIDS) }\end{array}$ & $\begin{array}{l}\text { Inflammatory cytokines } \\
\text { (through blood stream/afferent } \\
\text { vagus nerve) }\end{array}$ & $\begin{array}{l}\text { Inflammatory cytokines } \\
\text { (through blood stream/afferent } \\
\text { vagus nerve) }\end{array}$ & $\begin{array}{l}\text { Inflammatory cytokines (through } \\
\text { blood stream/afferent vagus } \\
\text { nerve) }\end{array}$ \\
\hline Sensors & $\begin{array}{l}\text { Chemoreceptive areas of the } \\
\text { midbrain }\end{array}$ & $\begin{array}{l}\text { Chemoreceptive areas of the } \\
\text { midbrain }\end{array}$ & $\begin{array}{l}\text { Chemoreceptive areas of the } \\
\text { midbrain }\end{array}$ \\
\hline $\begin{array}{l}\text { Mediated } \\
\text { through }\end{array}$ & Tracts and fibres of the SNS & ACTH in blood stream & Efferents of vagus nerve \\
\hline Effectors & Catecholamines & Glucocorticoids & Acetylcholine \\
\hline $\begin{array}{l}\text { Targets in } \\
\text { immune } \\
\text { system }\end{array}$ & $\begin{array}{l}\text { Lymphocytes, monocytes/ } \\
\text { macrophages, granulocytes }\end{array}$ & $\begin{array}{l}\text { Lymphocytes, monocytes/ } \\
\text { macrophages, granulocytes }\end{array}$ & Tissue macrophages \\
\hline
\end{tabular}

ACTH, adrenocorticotropic hormone; CARS, compensatory anti-inflammatory response syndrome; CIDS, CNS injury-induced immunodepression; HPA axis, hypothalamo-pituitary-adrenal axis; SNS, sympathetic nervous system.

The sympathetic nervous system. The SNS innervates both primary and secondary lymphoid organs, including the thymus, bone marrow, spleen, lymph nodes and mucosa-associated lymphoid tissues (for a review, see REF. 69). The extensive sympathetic innervation of immune organs and the presence of adrenergic receptors on almost all leukocytes indicate that immune function is strongly influenced by the level of sympathetic activity. Activation of the SNS causes the release of catecholamines (CAs) from sympathetic nerve terminals and from the adrenal medulla.

CAs induce a rapid, but transient, increase in blood lymphocyte counts and granulocytes. They appear to increase circulating leukocyte numbers by mobilizing cells from the marginal pool and peripheral reservoirs such as the spleen and lungs ${ }^{70}$. However, prolonged exposure to CAs decreases circulating lymphocyte numbers. CAs seem to selectively inhibit IFN $\gamma$ and IL-2 production by TYPE 1 T-HELPER T CELLS (Th1), but do not affect or even enhance TYPE 2 T-HELPER T CELL (Th2) cytokine production ${ }^{71,72}$. It is of note that $\beta_{2}$-adrenoreceptor ( $\beta_{2} \mathrm{AR}$ ) expression has been found on Th1 but not on Th2 cells, providing a molecular explanation for the observed differential effects of CAs on T-helper cell subsets ${ }^{72}$. As well as exerting direct inhibitory effects on Th1 cells, CAs suppress the capacity of antigen-presenting cells to induce Th1 cell responses, and $\beta_{2} A R$ activation inhibits the differentiation of naive CD4+ T cells to Th1 cells in an IL-12-dependent manner ${ }^{73}$. Several studies have shown that noradrenaline and adrenaline decrease the production of TNF $\alpha$, IL-1 $\beta$ and IL-12 by lipopolysaccharide (LPS)-stimulated monocytes, dendritic cells and human whole blood ${ }^{73-75}$. In addition, NK-cell activity, including cytotoxic activity and the production of effector molecules, is suppressed by $\mathrm{CAs}^{76-78}$.

In contrast to the inhibition of pro-inflammatory cytokines, CAs and $\beta_{2} \mathrm{AR}$ agonists increase the production of the anti-inflammatory cytokine IL-10 by LPS-stimulated monocytes and dendritic cells, and may even stimulate the release of preformed IL-10 from unstimulated monocytes ${ }^{45,74,75}$. In turn, increased IL-10 concentrations potently inhibit the pro-inflammatory and antigen-presenting capacity of monocytes/macrophages and dendritic cells, impairing their ability to initiate Th1 cell immune responses.

The parasympathetic nervous system. Recently, a novel bidirectional communication pathway between the nervous and immune systems was uncovered: the vagal 'cholinergic anti-inflammatory pathway', which results in a fast (real-time) and localized modulation of immune function (for reviews, see REFS 63,79). In response to acetylcholine, activated macrophages swiftly decrease the production of pro-inflammatory cytokines such as TNF $\alpha$, IL- $1 \beta$ and IL-18, but not the anti-inflammatory cytokine IL-10 (REF. 80). Very recently, the $\alpha-7$ nicotinic acetylcholine receptor, which is expressed on macrophages, was identified as the key target of cholinergic anti-inflammatory signalling ${ }^{81}$.

The hypothalmic-pituitary-adrenal axis. The end products of the HPA axis - glucocorticoids - have well known anti-inflammatory and immunosuppressive effects. They prevent inflammation by suppressing the production of many pro-inflammatory mediators, including cytokines (such as IL-1 $\beta$ and TNF $\alpha$ ), chemokines (IL-8), prostaglandins and nitric oxide ${ }^{82-84}$. By contrast, they may enhance the release of the anti-inflammatory mediators IL-10 and transforming growth factor- $\beta$ (TGF $\beta)^{85-87}$. Glucocorticoids also have strong anti-proliferative properties and induce apoptosis in eosinophils, and in immature and mature T lymphocytes, as well as in leukaemic cells ${ }^{88-91}$. Glucocorticoids enhance the resolution of inflammation by stimulating the production of acute phase reactants and by promoting antigen uptake by phagocytes ${ }^{84,92-94}$. On one hand, 
a

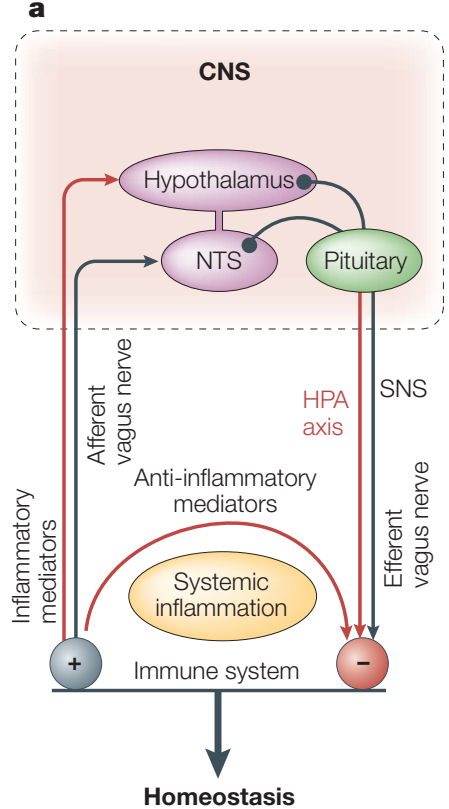

b

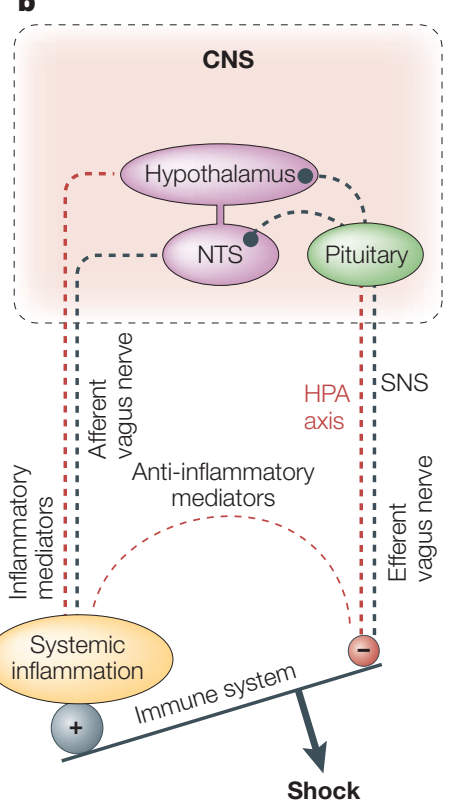

C

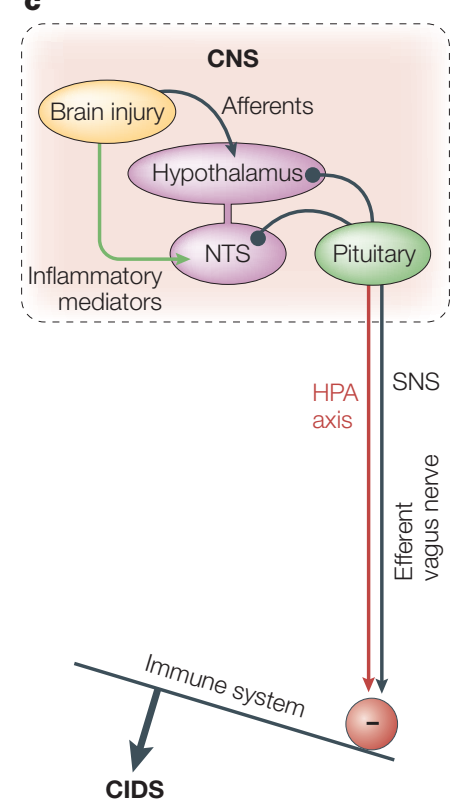

Neural Blood stream $\quad$ Diffusion

Figure 2 | Interactions between the central nervous system and the immune system. a | Systemic inflammation, as a result of bacterial infection or injury, is a potent stimulus of anti-inflammatory signalling by the CNS. Pro-inflammatory cytokines released during inflammation have a central role in wound healing and bacterial defence. To control inflammation, the CNS mounts a homeostatic, counter-regulatory anti-inflammatory response and brain-immune interaction helps to maintain homeostasis. b | Systemic infections or disturbed brain-immune interaction may result in overwhelming systemic inflammation: severe stresses such as sepsis can so strongly induce the systemic inflammatory response that there is an imbalanced anti-inflammatory counterregulation, and both responses contribute significantly to morbidity and mortality (from septic shock), as a result of either systemic inflammation or impaired antimicrobial defences. c | CNS inflammation without systemic inflammation may lead to active depression of peripheral immunity by the brain. When triggered in the absence of systemic inflammation, for example, by local diffusion of inflammatory cytokines after brain injury, an anti-inflammatory response may be triggered that is detrimental because it shuts down defence mechanisms, rendering the organism susceptible to infection. Under these conditions the immunodepression exerted by the brain is not balanced by general immunostimulation. CIDS, CNS injury-induced immunodepression; HPA axis, hypothalamopituitary-adrenal axis; NTS, nucleus tractus solitarius; SNS, sympathetic nervous system.

glucocorticoids decrease the capacity of monocytes/ macrophages and dendritic cells to present antigen to $\mathrm{T}$ lymphocytes and to elicit immune responses by downregulating the expression of MHC class II and co-stimulatory molecules (for example, CD86) (95,96. $^{2}$. In particular, glucocorticoids block differentiation of naive $\mathrm{T}$ cells to Th1 lymphocytes through the inhibition of monocytes/macrophages, dendritic cell-derived IL-12 secretion and IL-12 responsiveness of T cells ${ }^{97,98}$. On the other hand, glucocorticoids may promote differentiation of Th2 cells and give rise to the development of regulatory, IL-10-producing T cells ${ }^{86,99}$.

Secretion offactors from brain to blood after CNS injury. In addition to the neural and neurohumoral communication channels from the brain to the peripheral immune system, there is a third option for neuroimmunomodulation, which may be of particular relevance in CNS injury: the brain to blood transfer of cytokines and other immunomodulatory macromolecules. In contrast to the highly selective control of entry of substances from blood to brain through the blood-brain barrier, the exit of substances from the brain is nonselective and relatively rapid. From studies of brain tumours it is known that such tumours may induce immunosuppressive effects through the production of the pleiotrophic growth factor TGF $\beta^{100}$, and the anergic state of patients with glioblastoma is attributed to the brain-blood transfer of this cytokine ${ }^{101}$. TGF $\beta$ is also produced by astrocytes after brain trauma, ischaemia and/or increased intracranial pressure. After $\mathrm{TBI}^{102}$ and stroke ${ }^{103}$, increased serum levels of TGF $\beta$ have been measured. However, brain-derived IL-1 $\beta$, IL- 6 and IL-10, as well as other cytokines, have also been found to reach the systemic circulation after injury to the human brain ${ }^{28,104-109}$. The functional consequences of the secretion of immunomodulatory mediators from brain to blood after CNS injury remain to be established.

Other chemical mediators of neuroimmunomodulation. We have focused our discussion on a few prototypical cytokines (such as IL-1 $\beta$, TNF $\alpha$ and IL-6) and amines (such as adrenaline/epinephrine and noradrenaline), which have been called the common language of CNS-immune system communication. It should be noted, however, that this 'language' has a much more complex syntax and grammar, and includes the sensory neuropeptides calcitonin gene-related peptide (CGRP), 


\section{Box 1 |CIDS: accident or selected by evolution?}

Why do organisms react to CNS injury with such an apparently maladaptive response? Although compensatory anti-inflammatory response syndrome (CARS) may have evolved as a protective mechanism against excessive inflammation after infection or trauma, CNS injury-induced immunodepression (CIDS) could be viewed as its dysregulated, pathophysiological counterpart.

Alternatively, CIDS may have evolved as a protective response. During CNS injury self epitopes, which are normally shielded from the systemic immune system by a number of mechanisms, may become exposed to adaptive immunity. This may 'educate' the immune system to react to self antigens in the CNS, and, ultimately, lead to autoimmunity or autoaggression. According to this concept, by globally downregulating innate and adaptive immunity, CIDS may help to prevent postinjury autoagression. Indeed, after stroke and brain trauma brain-specific antigens can be measured in the blood plasma ${ }^{145}$, and $\mathrm{T}$ cells invade the brain ${ }^{146,147}$. At present, there is no epidemiological evidence that patients with stroke or brain trauma have an increased incidence of autoimmune CNS disorders (such as multiple sclerosis). This might point to effective control of autoimmunity under injury conditions, which would come at the price of an increased susceptibility to infection.

However, the interpretation of CIDS 'function' is complicated by the fact that a certain degree of autoimmunity may be needed for repair and regeneration after CNS injury ('protective autoimmunity'). According to this concept, injury of the CNS evokes a purposeful T-cell-mediated autoimmune response that reduces the injuryinduced degeneration in the $\mathrm{CNS}^{113}$. Whether and how $\mathrm{CIDS}$ might relate to protective autoimmunity is completely unknown.

COMPENSATORY ANTIINFLAMMATORY RESPONSE SYNDROME

(CARS). The systemic inflammatory response induces, and is then balanced by, counter-regulatory processes, known as CARS. This includes the release of anti-inflammatory molecules (for example, IL-10) and activation of neuroendocrine pathways (for example, the HPA axis). substance $\mathrm{P}$, neuropeptide Y (NPY) and vasoactive intestinal peptide (VIP), preproenkephaline products, melatonin and lipid derived mediators, among others. Each of these is produced by CNS cells as well as immune cells, which both carry their receptors. However, much less is known about whether and to what degree these latter mediators are involved as signals or effectors in neuroimmunomodulation after systemic injury, and almost nothing is known about their role after CNS injury.

\section{Immunodepression as a result of CNS injury}

Systemic inflammation resulting from bacterial infection or injury is a potent stimulus for anti-inflammatory signalling by the CNS: pro-inflammatory cytokines released during inflammation have a central role in wound healing and bacterial defence. However, excessive production of pro-inflammatory cytokines can lead to an overwhelming systemic inflammatory response (SIRS), which may result in shock and multiple organ failure. To control inflammation, the CNS, in addition to autoregulatory mechanisms of immune cells, mounts a homeostatic counter-regulatory anti-inflammatory response (COMPENSATORY ANTI-INFLAMMATORY RESPONSE SYNDROME, CARS) ${ }^{110,111}$ (FIG. 2a).

Ideally, inflammatory and anti-inflammatory responses to stress are balanced to allow containment of pathogens and wound healing, while preventing hyperinflammation or severe immunodepression. However, severe stresses such as sepsis ${ }^{112}$ can so strongly induce the systemic inflammatory response with an imbalanced anti-inflammatory counter-regulation that both contribute significantly to morbidity and mortality (septic shock), as a result of either systemic inflammation or impaired antimicrobial defences (FIG. 2b). A well balanced anti-inflammatory action of the nervous system appears to be beneficial in the presence of systemic inflammation. When triggered in the absence of systemic inflammation, however, this response may be detrimental, shutting down defence mechanisms and rendering the organism susceptible to infection (FIG. 2c). Under these conditions the immunodepression induced by the brain is not balanced by general immunostimulation. BOX 1 discusses whether CIDS may have evolved as an adaptive response to prevent the exposure of CNS epitopes to the immune system when the barrier between blood and the brain is severely disturbed. At present, it remains an open question as to whether CIDS is advantageous for the CNS, or whether its negative effects for the CNS (such as impairment of protective autoreactive immune responses ${ }^{113}$ ) should be added to the list of harmful consequences of immunodepression after CNS injury.

\section{CIDS induction by humoral signalling?}

The mechanisms by which CNS injury triggers the systemic anti-inflammatory response remain to be elucidated. Several lines of clinical and experimental evidence indicate that pro-inflammatory cytokines produced in the damaged brain tissue can directly induce HPA axis and SNS activation. Increased levels of cytokines such as IL- $1 \beta$, TNF $\alpha$ and IL- 6 in brain parenchyma and cerebrospinal fluid have been found in various brain disorders, including trauma, subarachnoid haemorrhage and ischaemia ${ }^{114}$. In patients with brain injury or stroke, elevated levels of IL- 6 released into the cerebrospinal fluid and plasma have been shown to correlate with increased plasma adrenocorticotropic hormone (ACTH) and cortisol concentrations ${ }^{28,115,116}$. In addition to central cytokine-mediated stimulation of the HPA axis, plasma IL-6 may increase cortisol secretion directly by augmenting adrenal function ${ }^{115,117}$. Furthermore, intracerebroventricular infusion of IL-1 $\beta$ in rats and primates results in rapid increases in plasma ACTH, glucocorticoid and catecholamine levels ${ }^{118-120}$. Finally, administration of IL-1 $\beta$ into the brain suppresses various cellular immune responses, including NK-cell activity, mitogen-induced T-cell proliferation and cytokine production, as well as monocyte/macrophage functions ${ }^{118,119,121,122}$. The involvement of HPA axis and SNS activation in brain IL-1 $\beta$-induced systemic immunosuppressive/immunosuppressant effects can be shown by either partial or total prevention of IL-1 $\beta$ induced changes by adrenalectomy, hypophysectomy or $\beta_{2} \mathrm{AR}$ antagonists ${ }^{118,121,122}$. Although these findings confirm the ability of raised intracerebral pro-inflammatory cytokine levels to activate the SNS and HPA axis, there is, so far, no formal proof that pro-inflammatory cytokines are the primary trigger of CIDS after CNS injury.

\section{CIDS induction by 'neurogenic' mechanisms?}

As outlined above, the release of pro-inflammatory cytokines in the CNS after injury may result in CIDS. Therefore, the possible mechanisms for triggering CIDS considered so far are similar to those responsible for 
NEUROGENIC

Caused by a primarily neuronal mechanism through either blockade or stimulation of trans-synaptic nerve conduction.

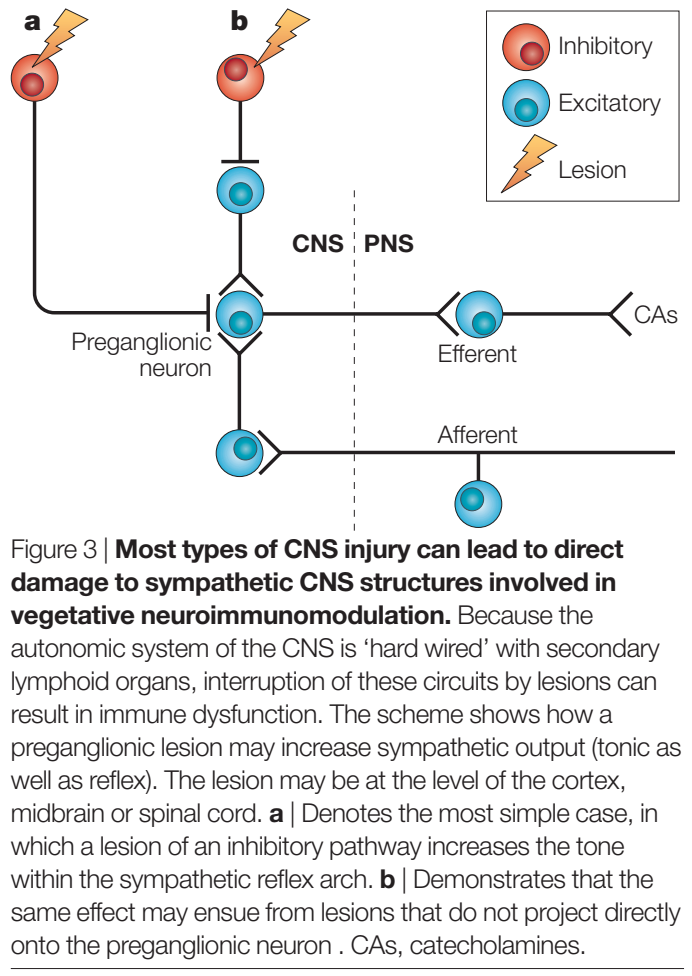

triggering anti-inflammation when injury occurs outside the CNS (CARS). In contrast to CARS, however, there may be additional, alternative pathways by which anti-inflammation and immunodepression are induced after the CNS has been injured, pathways that do not rely on cytokine signalling. Damage to sites in the nervous system that control neural-immune interactions (for example, the hypothalamus) can lead to NEUROGENIC

\section{Table 3 | Potential targets for the prevention and therapy of CIDS}

\section{Therapeutic agent Remarks \\ Central sensors of inflammation}

COX inhibitors, indomethacin, interleukin-1 receptor antagonist

$\beta_{2}$-adrenoreceptor antagonists, nicotinic acetylcholine receptor $\alpha-7$ subunit antagonists

Microsomal prostaglandin E synthase-1 (mPGES-1) inhibitors

\section{Immunomodulators}

Interferon- $\gamma$, G-CSF, GM-CSF, immunoglobulins

Thymomimetic drugs (such as thymulin and thymopentin)

Glucan (active component of zymosan)
Timing of treatment? Do these agents have negative systemic immunomodulatory effects?

Potential side effects (for example asthma and hypotension)

mPGES-1 is a central switch during immuneinduced pyrexia

Timing of treatment? Risk of worsening inflammation? CNS effects?

Have been shown to restore lymphocyte proliferative responses after open heart surgery

Stimulates macrophage activity, has been tested in patients undergoing abdominal surgery

\section{Anti-infectives}

Antibiotics

Currently given when infection is already clinically apparent. Preventive treatment?

CIDS, CNS injury-induced immunodepression; COX, cyclooxygenase; G-CSF, granulocyte colony-stimulating factor; GM-CSF, granulocyte-macrophage colony-stimulating factor. anti-inflammatory signals, without initial involvement of immune mechanisms. Although highly plausible, surprisingly little attention has been focused on such mechanisms, clinically or experimentally.

As the autonomic system of the CNS is 'hard wired' with secondary lymphoid organs, it comes as no surprise that interruption of these circuits can result in immune dysfunction. Most types of CNS injury can lead to direct damage of sympathetic CNS structures involved in vegetative neuroimmunomodulation. These are located in the brain (frontal pre-motor cortex, thalamus, hypothalamus, formatio reticularis, hippocampus, cerebellum and brain stem) and spinal cord (columna lateralis and nucleus intermediolateralis). Sympathetic neurons in the spinal cord innervate the adrenal medulla, thymus, spleen and lymph nodes ${ }^{123}$. A straightforward example of how damage to vegetative control centres may directly affect immunity can be seen in injury to the SNS of the spinal cord (FIG. 3). After SCI the peripheral vegetative nervous system may escape supraspinal control and display segmental sympathetic autonomy. This results in a 'sympathetic reflex-like condition', which, for example, may give rise to hypertensive episodes, headache or even cardiac arrest $^{124}$. These symptoms of autonomic dysfunction result from stimulation of the SNS below the level of injury and are a consequence of preganglionic injury, resulting in deafferentation of the CNS from the peripheral vegetative nervous system ${ }^{124}$. As sympathetic nervous stimulation leads to downregulation of innate and adaptive immunity, autonomic dysfunction may be accompanied by immunodepression. Therefore, disruption of preganglionic sympathetic pathways may cause 'reflex-like' sympathetic outflow to the lymphatic organs, resulting in immunodepression. This does not only apply to SCI, as autonomic dysfunction also occurs by similar mechanisms following stroke or TBI, when brainstem or midbrain structures of sympathetic control are affected ${ }^{125,126}$. For example, because the direct neural connection from the medial preoptic area to the paraventricular nucleus is inhibitory ${ }^{127}$, a lesion of the preoptic area or its fibres is predicted to trigger release of corticotropin-releasing factor from the paraventricular nucleus, with resultant SNS and HPA axis activation and reduction in cellular immunity.

Besides causing chronic autonomic dysfunction, trauma to sympathetic preganglionic neurons or synaptic deafferentation is accompanied acutely by a massive release of noradrenaline into sympathetic targets, including secondary lymphoid organs ${ }^{128,129}$. In the later stages after SCI, there is chronic depletion of noradrenaline release from sympathetic terminals, which is thought to induce alpha receptor hyper-responsiveness ${ }^{124,128}$.

Further support for the concept of an at least partially neurogenic nature of CIDS comes from studies on the lateralization of the autonomic nervous system in the brain. Lateralization of the structures of the vegetative nervous system ${ }^{130,131}$ might also serve to explain some localization-dependent effects of neural-immune interactions subsequent to a brain lesion ${ }^{132}$. For example, the severity of the immune deficit after a stroke is localization 


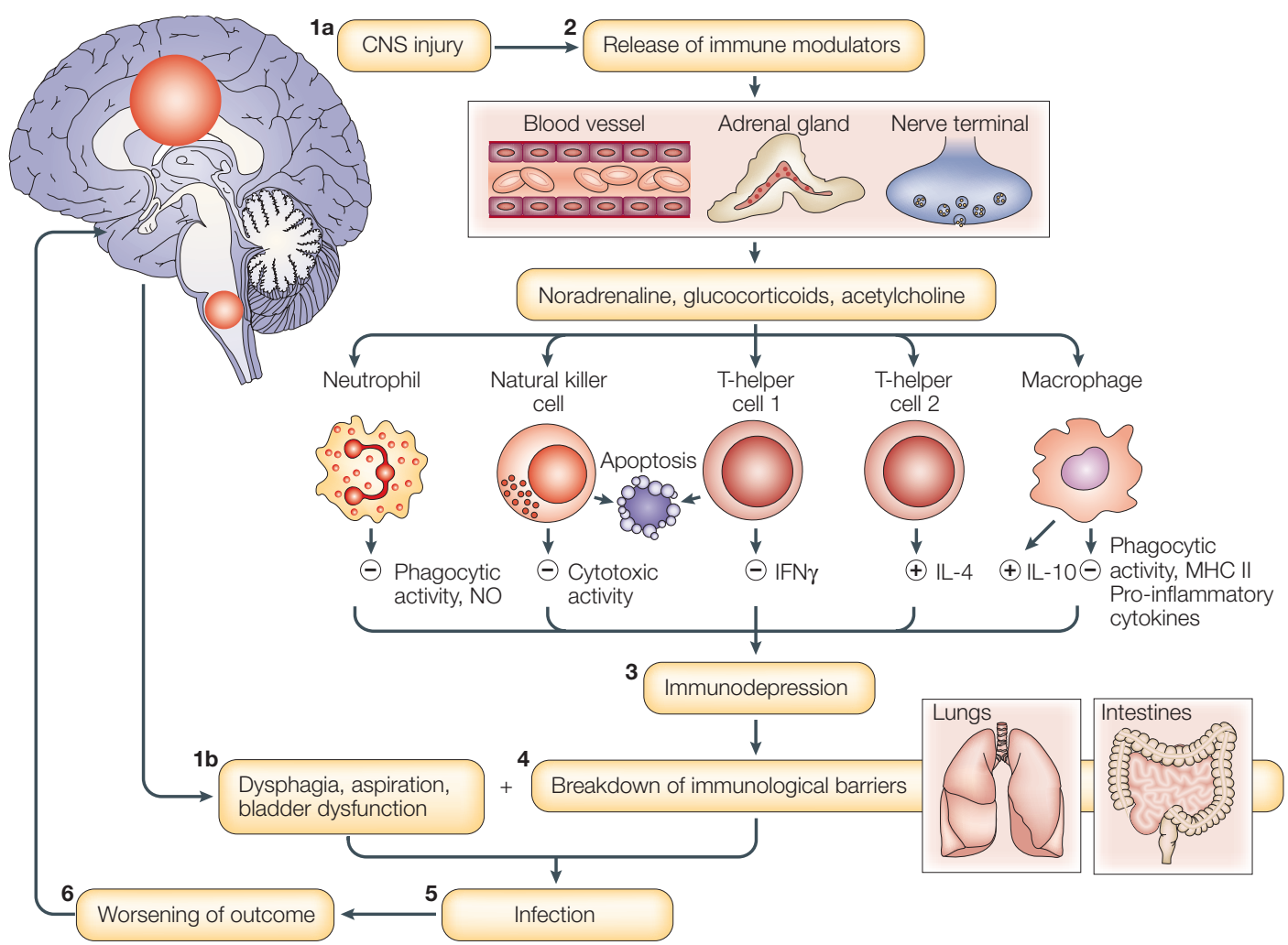

Figure 4 | Scheme summarizing the pathophysiological events that lead from CNS injury to infection and worsening of patient outcome. CNS injury (1a) induces a disturbance of the normally well balanced interplay between the immune system and the CNS. By inducing the local release of immune modulators (2), such as interleukins, CNS injury activates the hypothalamopituitary-adrenal axis, and the sympathetic and parasympathetic nervous systems. Through the release of noradrenaline, glucocorticoids and acetylcholine, a systemic anti-inflammatory response is mounted that negatively affects the function and composition of the innate and adaptive immune systems. As a consequence of the resulting immunodepression (3) and breakdown of immunological barriers (4), infection develops (5). The risk of infection is further increased because these patients are hospitalized under intensive care conditions and the CNS lesion itself may lead to dysphagia, aspiration, bladder dysfunction and so on (1b). Systemic infection increases morbidity and mortality in patients with CNS injury, and leads to worsening of outcome (6). IFN $\gamma$, interferon- $\gamma$, IL-4/10, interleukin-4/10; MHC II, major histocompatibility complex class II; NO, nitric oxide.

dependent. Cutaneous T-lymphocyte activity ipsilateral to the affected brain hemisphere has been shown to be significantly diminished in patients with right-sided hemiparesis compared with left-sided hemiparesis, which suggests that stronger immunosuppression occurs when the right side is involved ${ }^{133}$. Furthermore, lateralization is also reflected in vegetative dysfunction following stroke $e^{134,135}$. Interestingly, post-injury activation of the SNS was most pronounced when the insular cortex of the right hemisphere was affected ${ }^{126}$. The insular cortex receives projections from the nucleus tractus solitarius of the dorsal vagal complex in the medulla oblongata and projects to the amygdala and lateral hypothalamus. The insular cortex thereby has an important role in the higher control of the autonomic nervous system $^{136}$. Therefore, localization (for example, insular infarction) and, to a lesser extent, size of infarct may differentially affect the degree and type of autonomic dysfunction in stroke patients ${ }^{137}$.

Similarly, following SCI, the extent of vegetative dysfunction and corresponding immunodeficiency, which depends on lesion level, is correlated with the extent of sympathetic outflow deafferentation ${ }^{124,138}$.
SCI above thoracic level 6 results in marked reduction of intact sympathetic fibres and supraspinal control of the spleen, as well as the vasculature of the lower extremities $^{124}$. With regard to the immune system, complete tetraplegics, who are injured above the level of sympathetic outflow tracts, show a pronounced reduction in lymphocyte proliferation, responsiveness and NK-cell function. Moreover, the degree of immune dysfunction in SCI patients correlated well with the extent of deafferentation of the sympathetic outflow, with higher injuries inducing more severe immune dysfunction ${ }^{53}$.

Only a few studies have directly addressed the issue of the neurogenic mechanisms by which CNS lesions affect immune function. However, the evidence so far suggests that damage to vegetative control structures in the CNS plays an important part in the induction of CIDS.

\section{Therapeutic implications}

Patients with brain injury are at high risk of developing immunodepression and bacterial infections, which are major causes of morbidity and mortality in this patient population. It is therefore important for clinicians to 


\section{Box 2 | Open issues}

Although great progress has been made during recent decades in understanding the physiological interactions between the CNS and the immune system, little is known about the pathophysiology of the interaction of the two 'supersystems'. It has been clearly established that CNS injury is associated with an increased risk of infection, and it is well known that infection and its consequences are important contributors to outcome after CNS injury. It is also recognized that suppression of immune responses due to humoral and neurogenic signals after CNS injury at least partially underlies the increased susceptibility to infection. However, numerous questions remain to be answered, some of which are included below.

- Does the parasympathetic nervous system contribute to CNS injury-induced immunodepression (CIDS)? How does the CNS sense that it is injured? Which mediators, receptors, anatomical structures and pathways are involved?

-What is the differential relevance of neurogenic versus humoral mechanisms of CIDS?

- How does localization of brain injury affect the severity and characteristics of CIDS? Can brain imaging be used to predict the risk of developing CIDS?

- Does CIDS protect the CNS against autoaggression by invading immune cells? Does CIDS impede protective autoimmunity?

- Which parameters are useful for monitoring the immune status of patients with CNS injury? Can these parameters guide specific therapy?

- Should CIDS be treated by immunomodulation? If so, how and when should CIDS be treated?
Elevated intracranial pressure (ICP) is a common complication of brain injury. Increases in ICP induce sympathetic activation ${ }^{142,143}$, and may lead to the release of TGF $\beta$ and other cytokines from the brain into the blood (see above). To preserve cerebral perfusion pressure and avoid cardiovascular as well as pulmonary complications, monitoring and control of ICP is a primary goal in patients with CNS injury. We propose that avoidance of SNS activation-induced immunosuppression should be added to the list of negative consequences of intracranial hypertension.

At present, it is unclear whether direct intervention against CIDS is possible, and whether it would be effective in improving outcome. TABLE 3 lists potential targets for therapeutic modulation of CIDS. It should be noted that, besides immunoglobulins ${ }^{144}$, none of these agents have ever been tested in this indication. A number of unwanted side effects may severely restrict the use of several of these agents. In addition, given our ignorance concerning the 'function' of CIDS (BOX 1), it is conceivable that its blockade may foster autoaggressive reactions of the immune system against the CNS. Clearly, further basic research is needed before direct targeting of CIDS by immunomodulation can be clinically tested.

\section{Conclusions and future perspectives}

Although the study of neural-immune interactions during recent decades was biased towards studying the impact of the immune cells invading the CNS and their effectors, understanding the role of modulation of peripheral immune functions by the diseased CNS has received comparatively little attention. We do know that CNS injury, through the release of neuromodulators, downregulates the immune system, which may result in immunodepression, breakdown of immunological barriers and, consequently, infection (FIG. 4). Although it is emerging that brain-immune interactions after CNS injury have serious clinical implications, numerous issues remain to be resolved (BOX 2). CIDS is a prototypical example for pathological brain-immune interactions: CIDS after experimental stroke, TBI or SCI may serve as a model for the study of the mechanisms and mediators of control of brain over immunity during pathophysiological conditions. Even more importantly, understanding CIDS may eventually lead us to effective therapeutic strategies with which the outcome after CNS damage from a host of diseases might be improved by eliminating a major determinant of poor recovery.
1. Davenport, R. J., Dennis, M. S., Wellwood, I. \& Warlow, C. P. Complications after acute stroke. Stroke 27, 415-420 (1996). Langhorne, P. et al. Medical complications after stroke: a multicenter study. Stroke 31, 1223-1229 (2000). Weimar, C. et al. Complications following acute ischemic stroke. Eur. Neurol. 48, 133-140 (2002).

4. Hufeland, C. W. Enchiridion Medicum (Jonas Verlagsbuchhandlung, Berlin, 1836). Classical text book of clinical medicine (in German) containing a vivid description of the natural course of 'apoplexia', and possibly the first article to link fever and stroke.
5. Georgilis, K., Plomaritoglou, A., Dafni, U., Bassiakos, Y. \& Vemmos, K. Aetiology of fever in patients with acute stroke. J. Intern. Med. 246, 203-209 (1999).

6. Diez-Tejedor, E. \& Fuentes, B. Acute care in stroke: the importance of early intervention to achieve better brain protection. Cerebrovasc. Dis. 17 (Suppl. 1), 130-137 (2004).

7. Hajat, C., Hajat, S. \& Sharma, P. Effects of poststroke pyrexia on stroke outcome: a meta-analysis of studies in patients. Stroke 31, 410-414 (2000).

8. Grau, A. J. et al. Fever and infection early after ischemic stroke. J. Neurol. Sci. 171, 115-120 (1999).
9. Johnston, K. C. et al. Medical and neurological complications of ischemic stroke: experience from the RANTTAS trial. RANTTAS Investigators. Stroke 29, 447-453 (1998)

10. Kalra, L., Yu, G., Wilson, K. \& Roots, P. Medica complications during stroke rehabilitation. Stroke $\mathbf{2 6}$ 990-994 (1995).

11. Henon, H. et al. Early predictors of death and disability after acute cerebral ischemic event. Stroke 26, 392-398 (1995).

12. Rodriguez, R. et al, 3 year survival in patients hospitalized for acute cerebrovascular disorders. Rev. Neurol. 24 199-206 (1996). 
13. Vernino, S. et al. Cause-specific mortality after first cerebral infarction: a population-based study. Stroke 34, 1828-1832 (2003).

14. Heuschmann, P. U. et al. Predictors of in-hospital mortality and attributable risks of death after ischemic stroke: the German Stroke Registers Study Group. Arch. Intern. Med. 164, 1761-1768 (2004)

15. Hilker, R. et al. Nosocomial pneumonia after acute stroke: implications for neurological intensive care medicine. Stroke 34, 975-981 (2003).

16. Katzan, I. L., Cebul, R. D., Husak, S. H., Dawson, N. V. \& Baker, D. W. The effect of pneumonia on mortality among patients hospitalized for acute stroke. Neurology 60 620-625 (2003)

17. Nakajoh, K. et al. Relation between incidence of pneumonia and protective reflexes in post-stroke patients with oral or tube feeding. J. Intern. Med. 247, 39-42 (2000).

18. Marik, P. E. Aspiration pneumonitis and aspiration pneumonia. N. Engl. J. Med. 344, 665-671 (2001). Review article describing a concise concept of pneumonitis and pneumonia following aspiration, its differentiation and risk factors (for example, stroke).

19. Perry, L. \& Love, C. P. Screening for dysphagia and aspiration in acute stroke: a systematic review. Dysphagia 16, 7-18 (2001)

20. Nakagawa, T. et al. Silent cerebral infarction: a potential risk for pneumonia in the elderly. J. Intern. Med. 247, 255-259 (2000).

21. Fabregas, N. \& Torres, A. Pulmonary infection in the brain injured patient. Minerva Anestesiol. 68, 285-290 (2002).

22. Piek, J. et al. Extracranial complications of severe head injury. J. Neurosurg. 77, 901-907 (1992).

23. Chastre, J. \& Fagon, J. Y. Ventilator-associated pneumonia Am. J. Respir. Crit. Care Med. 165, 867-903 (2002)

24. Bronchard, R. et al. Early onset pneumonia: risk factors and consequences in head trauma patients. Anesthesiology 100, 234-239 (2004)

25. Ewig, S. et al. Bacterial colonization patterns in mechanically ventilated patients with traumatic and medical head injury. Incidence, risk factors, and association with ventilatorassociated pneumonia. Am. J. Respir. Crit. Care Med. 159 188-198 (1999)

26. Woratyla, S. P., Morgan, A. S., Mackay, L., Bernstein, B. \& Barba, C. Factors associated with early onset pneumonia in the severely brain-injured patient. Conn. Med. 59, 643-647 (1995).

27. Campbell, W., Hendrix, E., Schwalbe, R., Fattom, A. \& Edelman, R. Head-injured patients who are nasal carriers of Staphylococcus aureus are at high risk for Staphylococcus aureus pneumonia. Crit. Care Med. 27 798-801 (1999).

28. Woiciechowsky, C. et al. Early IL-6 plasma concentrations correlate with severity of brain injury and pneumonia in brain-injured patients. J. Trauma 52, 339-345 (2002)

29. Ishikawa, K. et al. Characteristics of infection and leukocyte count in severely head-injured patients treated with mild hypothermia. J. Trauma 49, 912-922 (2000).

30. Nadal, P., Nicolas, J. M., Font, C., Vilella, A. \& Nogue, S. Pneumonia in ventilated head trauma patients: the role of thiopental therapy. Eur. J. Emerg. Med. 2, 14-16 (1995).

31. Kollef, M. H., Silver, P., Murphy, D. M. \& Trovillion, E. The effect of late-onset ventilator-associated pneumonia in determining patient mortality. Chest 108, 1655-1662 (1995).

32. Sirvent, J. M. et al. Protective effect of intravenously administered cefuroxime against nosocomial pneumonia in patients with structural coma. Am. J. Respir. Crit. Care Med. 155, 1729-1734 (1997).

33. Jackson, A. B. \& Groomes, T. E. Incidence of respiratory complications following spinal cord injury. Arch. Phys. Med. Rehabil. 75, 270-275 (1994).

34. Waites, K. B., Canupp, K. C., Chen, Y., DeVivo, M. J. \& Moser, S. A. Bacteremia after spinal cord injury in initia versus subsequent hospitalizations. J. Spinal Cord Med. 24 96-100 (2001)

35. DeVivo, M. J., Black, K. J. \& Stover, S. L. Causes of death during the first 12 years after spinal cord injury. Arch. Phys. Med. Rehabil. 74, 248-254 (1993).

References 33-37 detail seminal work using the SCI model system, which reports and quantifies infectious complications after $\mathrm{SCl}$. They provide a clinical-epidemiological hint for a relative state of anergia attributable to $\mathrm{SCl}$.

36. DeVivo, M. J., Krause, J. S. \& Lammertse, D. P. Recent trends in mortality and causes of death among persons with spinal cord injury. Arch. Phys. Med. Rehabil. 80, 1411-1419 (1999).

37. Ragnarsson, K. T., Carter, R. E., Wilmot, C. B. \& Hall, K. M. Spinal Cord Injury: Clinical Outcomes from the Model Systems (eds Stover, S. L., Whiteneck, G. G. \& deLisa, J. A.) 79-99 (Aspen Publishers Inc, USA, 1995).
38. Reines, H. D. \& Harris, R. C. Pulmonary complications of acute spinal cord injuries. Neurosurgery 21, 193-196 (1987).

39. Inamasu, J., Nakamura, Y. \& Ichikizaki, K. Induced hypothermia in experimental traumatic spinal cord injury: an update. J. Neurol. Sci. 209, 55-60 (2003).

40. Meisel, C. et al. Preventive antibacterial treatment improves the general medical and neurological outcome in a mouse model of stroke. Stroke 35, 2-6 (2004).

41. Cruse, J. M., Lewis, R. E., Bishop, G. R., Kliesch, W. F. \& Gaitan, E. Neuroendocrine-immune interactions associated with loss and restoration of immune system function in spinal cord injury and stroke patients. Immunol. Res. 11, 104-116 (1992)

42. Czlonkowska, A., Cyrta, B. \& Korlak, J. Immunologica observations on patients with acute cerebral vascular disease. J. Neurol. Sci. 43, 455-464 (1979). One of the first clinical studies demonstrating a marked inhibition of cell-mediated immune responses in patients after cerebral infarction, including suppressed DTH skin reactivity and reduced mitogenic T-cell responses, which correlated with disease severity.

43. Hoyt, D. B., Ozkan, A. N., Hansbrough, J. F., Marshall, L. \& van Berkum-Clark, M. Head injury: an immunologic deficit in T-cell activation. J. Trauma 30, 759-766 (1990).

44. Quattrocchi, K. B. et al. Impairment of helper T-cell function and lymphokine-activated killer cytotoxicity following severe head injury. J. Neurosurg. 75, 766-773 (1991).

45. Woiciechowsky, C. et al. Sympathetic activation triggers systemic interleukin-10 release in immunodepression induced by brain injury. Nature Med. 4, 808-813 (1998). Important study linking brain injury with immunodepression caused by sympathetic overactivation

46. Kossmann, T. et al. Intrathecal and serum interleukin-6 and the acute-phase response in patients with severe traumatic brain injuries. Shock 4, 311-317 (1995).

47. Meert, K. L., Long, M., Kaplan, J. \& Sarnaik, A. P. Alterations in immune function following head injury in children. Crit. Care Med. 23, 822-828 (1995).

48. Quattrocchi, K. B. et al. Severe head injury: effect upon cellular immune function. Neurol. Res. 13, 13-20 (1991).

49. Imhoff, M., Gahr, R. H. \& Hoffmann, P. Delayed cutaneous hypersensitivity after multiple injury and severe burn. Ann Ital. Chir. 61, 525-528 (1990).

50. Miller, C. H., Quattrocchi, K. B., Frank, E. H., Issel, B. W. \& Wagner, F. C. Jr. Humoral and cellular immunity following severe head injury: review and current investigations. Neurol. Res. 13, 117-124 (1991).

51. Wolach, B., Sazbon, L., Gavrieli, R., Broda, A. \& Schlesinger, M. Early immunological defects in comatose patients after acute brain injury. J. Neurosurg. 94, 706-711 (2001).

52. Maerker-Alzer, G., Beckmann, H., Richard, K. E. \& Frowein, R. A. Humoral immunodeficiency syndrome in patients with severe head injury? Neurosurg. Rev. 12 (Suppl. 1), 420-428 (1989)

53. Campagnolo, D. I., Bartlett, J. A., Keller, S. E., Sanchez, W. \& Oza, R. Impaired phagocytosis of Staphylococcus aureus in complete tetraplegics. Am. J. Phys. Med. Rehabil. 76, 276-280 (1997).

One of the earliest studies documenting impaired host defence as a function of a hampered innate immune response (immune-suppression) following SCl.

54. Huschak, G., Zur, N. K., Stuttmann, R. \& Riemann, D. Changes in monocytic expression of aminopeptidase N/ CD13 after major trauma. Clin. Exp. Immunol. 134, 491-496 (2003).

55. Wolk, K., Docke, W. D., von Baehr, V., Volk, H. D. \& Sabat, R. Impaired antigen presentation by human monocytes during endotoxin tolerance. Blood $\mathbf{9 6}$ 218-223 (2000).

56. Asadullah, K. et al. Immunodepression following neurosurgical procedures. Crit. Care Med. 23, 1976-1983 (1995).

57. Majetschak, M. et al. The extent of traumatic damage determines a graded depression of the endotoxin responsiveness of peripheral blood mononuclear cells from patients with blunt injuries. Crit. Care Med. 27, 313-318 (1999).

58. Prass, K. et al. Stroke-induced immunodeficiency promotes spontaneous bacterial infections and is mediated by sympathetic activation reversal by poststroke Thelper cell type 1-like immunostimulation. J. Exp. Med. 198, 725-736 (2003).

Provides experimental proof, for the first time, that a neuroendocrine-mediated systemic immunosuppression after acute brain injury results in the development of spontaneous systemic bacterial infections.
59. Elenkov, I. J., Wilder, R. L., Chrousos, G. P. \& Vizi, E. S. The sympathetic nerve-an integrative interface between two supersystems: the brain and the immune system. Pharmacol. Rev. 52, 595-638 (2000).

Comprehensive review on the role of the sympathetic nerve in the interactions between the brain and the immune system.

60. Pavlov, V. A. \& Tracey, K. J. Neural regulators of innate immune responses and inflammation. Cell. Mol. Life Sci. 61, 2322-2331 (2004).

61. Steinman, L. Elaborate interactions between the immune and nervous systems. Nature Immunol. 5, 575-581 (2004).

62. Mulla, A. \& Buckingham, J. C. Regulation of the hypothalamo-pituitary-adrenal axis by cytokines. Baillieres Best. Pract. Res. Clin. Endocrinol. Metab. 13, 503-521 (1999).

63. Pavlov, V. A., Wang, H., Czura, C. J., Friedman, S. G. \& Tracey, K. J. The cholinergic anti-inflammatory pathway: a missing link in neuroimmunomodulation. Mol. Med. $\mathbf{9}$ 125-134 (2003).

64. Goehler, L. E. et al. Vagal immune-to-brain communication: a visceral chemosensory pathway. Auton Neurosci. 85, 49-59 (2000).

65. Banks, W. A., Kastin, A. J. \& Broadwell, R. D. Passage of cytokines across the blood-brain barrier. Neuroimmunomodulation 2, 241-248 (1995).

66. Buller, K. M. Role of circumventricular organs in proinflammatory cytokine-induced activation of the hypothalamic-pituitary-adrenal axis. Clin. Exp. Pharmacol. Physiol. 28, 581-589 (2001)

67. Weindl, A. in Frontiers in Neuroendocrinology (eds Ganong, W. F. \& Martini, L.) 3-32 (Oxford Univ. Press, New York, 1973).

68. Haddad, J. J., Saade, N. E. \& Safieh-Garabedian, B. Cytokines and neuro-immune-endocrine interactions: a role for the hypothalamic-pituitary-adrenal revolving axis. J. Neuroimmunol. 133, 1-19 (2002).

69. Felten, D. L. et al. Noradrenergic sympathetic neural interactions with the immune system: structure and function. Immunol. Rev. 100, 225-260 (1987).

70. Benschop, R. J., Rodriguez-Feuerhahn, M. \& Schedlowski, M. Catecholamine-induced leukocytosis: early observations, current research, and future directions. Brain Behav. Immun. 10, 77-91 (1996).

71. Borger, P. et al. $\beta$-adrenoceptor-mediated inhibition of IFN- $\gamma$, IL-3, and GM-CSF mRNA accumulation in activated human $T$ lymphocytes is solely mediated by the $\beta 2$ adrenoceptor subtype. Am. J. Respir. Cell Mol. Biol. 19 400-407 (1998)

72. Sanders, V. M. et al. Differential expression of the 32 -adrenergic receptor by Th1 and Th2 clones: implications for cytokine production and B cell help. J. Immunol. 158, 4200-4210 (1997).

73. Panina-Bordignon, P. et al. $\beta 2$-agonists prevent Th1 development by selective inhibition of interleukin 12 . J. Clin. Invest. 100, 1513-1519 (1997).

74. Elenkov, I. J., Papanicolaou, D. A., Wilder, R. L. \& Chrousos, G. P. Modulatory effects of glucocorticoids and catecholamines on human interleukin-12 and interleukin10 production: clinical implications. Proc. Assoc. Am. Physicians 108, 374-381 (1996).

75. Van der Poll, T., Coyle, S. M., Barbosa, K., Braxton, C. C. \& Lowry, S. F. Epinephrine inhibits tumor necrosis factor- $\alpha$ and potentiates interleukin 10 production during human endotoxemia. J. Clin. Invest. 97, 713-719 (1996).

76. Dokur, M., Boyadjieva, N. \& Sarkar, D. K. Catecholaminergic control of NK cell cytolytic activity regulatory factors in the spleen. J. Neuroimmunol. 151 148-157 (2004)

77. Shakhar, G. \& Ben Eliyahu, S. In vivo $\beta$-adrenergic stimulation suppresses natural killer activity and compromises resistance to tumor metastasis in rats. J. Immunol. 160, 3251-3258 (1998).

78. Takamoto, T. et al. Norepinephrine inhibits human natural killer cell activity in vitro. Int. J. Neurosci. 58, 127-131 (1991).

79. Tracey, K. J. The inflammatory reflex. Nature $\mathbf{4 2 0}$, 853-859 (2002).

80. Borovikova, L. V. et al. Vagus nerve stimulation attenuates the systemic inflammatory response to endotoxin. Nature 405, 458-462 (2000)

The first report to demonstrate a neural antiinflammatory pathway, consisting of afferent and efferent vagus nerve signalling, through which the CNS modulates systemic inflammatory responses.

81. Wang, $H$. et al. Nicotinic acetylcholine receptor $\alpha 7$ subunit is an essential regulator of inflammation. Nature $\mathbf{4 2 1}$ 384-388 (2003).

82. Kwon, $\mathrm{O}$. J. et al. Inhibition of interleukin-8 expression by dexamethasone in human cultured airway epithelial cells. Immunology 81, 389-394 (1994). 
83. Szabo, C., Thiemermann, C., Wu, C. C., Perretti, M. \& Vane, J. R. Attenuation of the induction of nitric oxide synthase by endogenous glucocorticoids accounts for endotoxin tolerance in vivo. Proc. Natl Acad. Sci. USA 91, 271-275 (1994)

84. Wilckens, T. \& De Rijk, R. Glucocorticoids and immune function: unknown dimensions and new frontiers. Immunol. Today 18, 418-424 (1997)

85. AyanlarBatuman, O., Ferrero, A. P., Diaz, A. \& Jimenez, S. A. Regulation of transforming growth factor- $\beta 1$ gene expression by glucocorticoids in normal human lymphocytes. J. Clin. Invest. 88, 1574-1580 (1991).

86. Barrat, F. J. et al. In vitro generation of interleukin 10-producing regulatory $\mathrm{CD} 4^{+} \mathrm{T}$ cells is induced by immunosuppressive drugs and inhibited by T helper type 1 (Th1)- and Th2-inducing cytokines. J. Exp. Med. 195 603-616 (2002).

87. Hodge, S., Hodge, G., Flower, R. \& Han, P. Methylprednisolone up-regulates monocyte interleukin-10 production in stimulated whole blood. Scand. J. Immunol. 49, 548-553 (1999)

88. Meagher, L. C., Cousin, J. M., Seckl, J. R. \& Haslett, C. Opposing effects of glucocorticoids on the rate of apoptosis in neutrophilic and eosinophilic granulocytes. J. Immunol. 156, 4422-4428 (1996).

89. Smets, L. A., Salomons, G. \& van den Berg, J. Glucocorticoid induced apoptosis in leukemia. Adv. Exp. Med. Biol. 457, 607-614 (1999).

90. Tuosto, L., Cundari, E., Montani, M. S. \& Piccolella, E. Analysis of susceptibility of mature human $\mathrm{T}$ lymphocytes to dexamethasone-induced apoptosis. Eur. J. Immunol. 24 1061-1065 (1994).

91. Zacharchuk, C. M., Mercep, M., Chakraborti, P. K., Simons, S. S. Jr. \& Ashwell, J. D. Programmed T lymphocyte death. Cell activation- and steroid-induced pathways are mutually antagonistic. J. Immunol. 145, 4037-4045 (1990).

92. Cowan, H. B., Vick, S., Conary, J. T. \& Shepherd, V. L. Dexamethasone up-regulates mannose receptor activity by increasing mRNA levels. Arch. Biochem. Biophys. 296 314-320 (1992)

93. Liu, Y. et al. Glucocorticoids promote nonphlogistic phagocytosis of apoptotic leukocytes. J. Immunol. 162, 3639-3646 (1999).

94. Piemonti, L. et al. Glucocorticoids increase the endocytic activity of human dendritic cells. Int. Immunol. 11 1519-1526 (1999)

95. Pan, J. et al. Dexamethasone inhibits the antigen presentation of dendritic cells in $\mathrm{MHC}$ class II pathway. Immunol. Lett. 76, 153-161 (2001).

96. Schwiebert, L. M., Schleimer, R. P., Radka, S. F. \& Ono, S. J. Modulation of $\mathrm{MHC}$ class II expression in human cells by dexamethasone. Cell. Immunol. 165, 12-19 (1995).

97. Blotta, M. H., DeKruyff, R. H. \& Umetsu, D. T. Corticosteroids inhibit IL-12 production in human monocytes and enhance their capacity to induce IL-4 synthesis in CD4+ lymphocytes. J. Immunol. 158 5589-5595 (1997).

98. Franchimont, D. et al. Inhibition of Th1 immune response by glucocorticoids: dexamethasone selectively inhibits IL-12induced Stat4 phosphorylation in T lymphocytes. J. Immunol. 164, 1768-1774 (2000).

99. Ramierz, F., Fowell, D. J., Puklavec, M., Simmonds, S. \& Mason, D. Glucocorticoids promote a TH2 cytokine response by CD4+ T cells in vitro. J. Immunol. 156, 2406-2412 (1996)

100. Weller, M. \& Fontana, A. The failure of current immunotherapy for malignant glioma. Tumor-derived TGF- $\beta$, T-cell apoptosis, and the immune privilege of the brain. Brain Res. Rev. 21, 128-151 (1995)

101. Bodmer, S., Huber, D., Heid, I. \& Fontana, A. Human glioblastoma cell derived transforming growth-factor- $\beta$-2: evidence for secretion of both high and low-molecularweight biologically-active forms. J. Neuroimmunol. 34 33-42 (1991).

102. Csuka, E. et al. IL-10 levels in cerebrospinal fluid and serum of patients with severe traumatic brain injury: relationship to IL-6, TNF- $\alpha$, TGF- $\beta 1$ and blood-brain barrier function. J. Neuroimmunol. 101, 211-221 (1999).

103. Stanzani, L. et al. Nerve growth factor and transforming growth factor- $\beta$ serum levels in acute stroke patients: possible involvement of neurotrophins in cerebrovascular disease. Cerebrovasc. Dis. 12, 240-244 (2001).

104. Castillo, J. et al. The release of tumor necrosis factor- $\alpha$ is associated with ischemic tolerance in human stroke. An Neurol. 54, 811-819 (2003).

105. Emsley, H. C. et al. An early and sustained peripheral inflammatory response in acute ischaemic stroke: relationships with infection and atherosclerosis. J. Neuroimmunol. 139, 93-101 (2003).

106. Grau, A. J. et al. Monocyte function and plasma levels of interleukin-8 in acute ischemic stroke. J. Neurol. Sci. 192 41-47 (2001).
107. Smith, C. J. et al. Peak plasma interleukin-6 and other peripheral markers of inflammation in the first week of ischaemic stroke correlate with brain infarct volume, stroke severity and long-term outcome. BMC Neurol. 4, 2 (2004).

108. Vila, N., Castillo, J., Davalos, A. \& Chamorro, A. Proinflammatory cytokines and early neurological worsening in ischemic stroke. Stroke 31, 2325-2329 (2000).

109. Vila, N. et al. Levels of anti-inflammatory cytokines and neurological worsening in acute ischemic stroke. Stroke 34, 671-675 (2003).

110. Bone, R. C. Immunologic dissonance: a continuing evolution in our understanding of the systemic inflammatory response syndrome (SIRS) and the multiple organ dysfunction syndrome (MODS). Ann. Intern. Med. 125, 680-687 (1996).

111. Woiciechowsky, C. Schoning, B., Lanksch, W. R., Volk, H. D. \& Docke, W. D. Mechanisms of brain-mediated systemic anti-inflammatory syndrome causing immunodepression. J. Mol. Med. 77, 769-780 (1999).

112. Sharshar, T., Hopkinson, N. S., Orlikowski, D. \& Annane, D. Science review: the brain in sepsis - culprit and victim. Crit. Care 9, 37-44 (2005)

113. Schwartz, M. Harnessing the immune system for neuroprotection: therapeutic vaccines for acute and chronic neurodegenerative disorders. Cell. Mol. Neurobiol. 21, 617-627 (2001)

114. Feuerstein, G. Z., Liu, T. \& Barone, F. C. Cytokines, inflammation, and brain injury: role of tumor necrosis factor- $\alpha$. Cerebrovasc. Brain Metab. Rev. 6, 341-360 (1994).

115. Johansson, A., Olsson, T., Carlberg, B., Karlsson, K. \& Fagerlund, M. Hypercortisolism after stroke-partly cytokine-mediated? J. Neurol. Sci. 147, 43-47 (1997)

116. Szczudlik, A., Dziedzic, T., Bartus, S., Slowik, A. \& Kieltyka, A. Serum interleukin-6 predicts cortisol release in acute stroke patients. J. Endocrinol. Invest. 27, 37-41 (2004).

117. Bethin, K. E., Vogt, S. K. \& Muglia, L. J. Interleukin-6 is an essential, corticotropin-releasing hormone-independent stimulator of the adrenal axis during immune system activation. Proc. Natl Acad. Sci. USA 97, 9317-9322 (2000).

118. Brown, R. et al. Suppression of splenic macrophage interleukin-1 secretion following intracerebroventricular injection of interleukin-1 $\beta$ : evidence for pituitary-adrenal and sympathetic control. Cell. Immunol. 132, 84-93 (1991).

119. Sullivan, G. M. et al. Intracerebroventricular injection of interleukin-1 suppresses peripheral lymphocyte function in the primate. Neuroimmunomodulation 4, 12-18 (1997).

120. van der Meer, M. J. et al. Acute stimulation of the hypothalamic-pituitary-adrenal axis by IL-1 $\beta$, TNF $\alpha$ and IL-6: a dose response study. J. Endocrinol. Invest. 19, 175-182 (1996)

121. Sundar, S. K. et al. Intracerebroventricular infusion of interleukin 1 rapidly decreases peripheral cellular immune responses. Proc. Natl Acad. Sci. USA 86, 6398-6402 (1989).

122. Woiciechowsky, C. et al. Brain-IL-1ß induces local inflammation but systemic anti-inflammatory response through stimulation of both hypothalamic-pituitary-adrena axis and sympathetic nervous system. Brain Res. $\mathbf{8 1 6}$ 563-571 (1999).

123. Stevens-Felten, S. Y. \& Bellinger, D. L. Noradrenergic and peptidergic innervation of lymphoid organs. Chem. Immunol. 69, 99-131 (1997).

124. Teasell, R. W., Arnold, J. M., Krassioukov, A. \& Delaney, G. A. Cardiovascular consequences of loss of supraspinal control of the sympathetic nervous system after spinal cord injury. Arch. Phys. Med. Rehabil. 81, 506-516 (2000).

125. Chesnut, R. M., Gautille, T., Blunt, B. A., Klauber, M. R. \& Marshall, L. F. Neurogenic hypotension in patients with severe head injuries. J. Trauma 44, 958-963 (1998).

126. Meyer, S., Strittmatter, M., Fischer, C., Georg, T. \& Schmitz, B. Lateralization in autonomic dysfunction in ischemic stroke involving the insular cortex. Neuroreport 15, 357-361 (2004)

127. Saphier, D. \& Feldman, S. Effects of stimulation of the preoptic area on hypothalamic paraventricular nucleus unit activity and corticosterone secretion in freely moving rats. Neuroendocrinology 42, 167-173 (1986).

128. Tibbs, P. A., Young, B., Ziegler, M. G. \& McAllister, R. G. Jr. Studies of experimental cervical spinal cord transection. Part II: plasma norepinephrine levels after acute cervical spinal cord transection. J. Neurosurg. 50, 629-632 (1979).

129. Feibel, J. H., Hardy, P. M., Campbell, R. G., Goldstein, M. N. \& Joynt, R. J. Prognostic value of the stress response following stroke. JAMA 238, 1374-1376 (1977)

130. Harper, R. M., Bandler, R., Spriggs, D. \& Alger, J. R. Lateralized and widespread brain activation during transient blood pressure elevation revealed by magnetic resonance imaging. J. Comp. Neurol. 417, 195-204 (2000).
131. Kalogeras, K. T. et al. Inferior petrosal sinus sampling in healthy subjects reveals a unilateral corticotropin-releasing hormone-induced arginine vasopressin release associated with ipsilateral adrenocorticotropin secretion. J. Clin. Invest. 97, 2045-2050 (1996).

132. Meador, K. J. et al. Role of cerebral lateralization in control of immune processes in humans. Ann. Neurol. 55, 840-844 (2004)

133. Tarkowski, E. et al. Localization of the brain lesion affects the lateralization of T-lymphocyte dependent cutaneous inflammation. Evidence for an immunoregulatory role of the right frontal cortex-putamen region. Scand. J. Immunol. 47 30-36 (1998)

134. Robinson, R. G. Differential behavioral and biochemical effects of right and left hemispheric cerebral infarction in the rat. Science 205, 707-710 (1979).

135. Tarkowski, E., Naver, H., Wallin, B. G., Blomstrand, C. \& Tarkowski, A. Lateralization of T-lymphocyte responses in patients with stroke. Effect of sympathetic dysfunction? Stroke 26, 57-62 (1995)

136. Cechetto, D. F. \& Chen, S. J. Subcortical sites mediating sympathetic responses from insular cortex in rats. $\mathrm{Am}$. J. Physiol. 258, R245-R255 (1990).

137. Sander, D. \& Klingelhofer, J. Changes of circadian blood pressure patterns and cardiovascular parameters indicate lateralization of sympathetic activation following hemispheric brain infarction. J. Neurol. 242, 313-318 (1995).

138. Popovich, P. G. Immunological regulation of neuronal degeneration and regeneration in the injured spinal cord. Prog. Brain Res. 128, 43-58 (2000).

139. Evans, A. et al. Can differences in management processes explain different outcomes between stroke unit and stroketeam care? Lancet 358, 1586-1592 (2001).

140. Ronning, O. M. \& Guldvog, B. Stroke unit versus general medical wards, II: neurological deficits and activities of daily living: a quasi-randomized controlled trial. Stroke $\mathbf{2 9}$ 586-590 (1998).

141. Ronning, O. M. \& Guldvog, B. Stroke units versus genera medical wards, I: twelve- and eighteen-month survival: a randomized, controlled trial. Stroke 29, 58-62 (1998).

142. Furuichi, S. et al. Related changes in sympathetic activity, cerebral blood flow and intracranial pressure, and effect of an alpha-blocker in experimental subarachnoid haemorrhage. Acta Neurochir. Wien.) 141, 415-423 (1999).

143. Naredi, S. et al. Increased sympathetic nervous activity in patients with nontraumatic subarachnoid hemorrhage. Stroke 31, 901-906 (2000).

144. Palasik, W., Popow, J., Lechowicz, W., Fiszer, U. \& Czlonkowska, A. The use of gammaglobulin for preventing infection in stroke. Neurol. Neurochir. Pol. 29, 309-316 (1995)

145. Strand, T., Alling, C., Karlsson, B., Karlsson, I. \& Winblad, B. Brain and plasma proteins in spinal fluid as markers for brain damage and severity of stroke. Stroke 15, 138-144 (1984).

146. Becker, K., Kindrick, D., McCarron, R., Hallenbeck, J. \& Winn, R. Adoptive transfer of myelin basic protein-tolerized splenocytes to naive animals reduces infarct size: a role for lymphocytes in ischemic brain injury? Stroke $\mathbf{3 4}$, 1809-1815 (2003)

Study showing that immunological tolerance and its neuroprotective effects in stroke can be transferred to naive animals and are related to antigen-specific induction of transforming growth factor- $\beta 1$.

147. Schwab, J. M. Nguyen, T. D., Meyermann, R. \&

Schluesener, H. J. Human focal cerebral infarctions induce differential lesional interleukin-16 (IL-16) expression confined to infiltrating granulocytes, CD8+ T-lymphocytes and activated microglia/macrophages. J. Neuroimmunol. 114, 232-241 (2001).

Acknowledgements

The authors' work is supported by the Hermann and Lilly Schilling Foundation, the Wings for Life Spinal Cord Research Foundation, and the Deutsche Forschungsgemeinschaft.

Competing interests statement

The authors declare competing financial interests: see Web version for details.

\section{(2) Online links}

\section{DATABASES}

The following terms in this article are linked online to: Entrez Gene: http://www.ncbi.nlm.nih.gov/entrez/query. fcgi?db=gene

ACTH | CGRP | CRF | IFN $\mid$ | IL-1 | | IL-6 | NPY | TNF $\alpha$ | VIP

FURTHER INFORMATION

Department of Experimental Neurology, Charité, Berlin: http://www.expneuro.de

Access to this interactive links box is free online. 